\title{
EFEITO DA ÉPOCA DE SEMEADURA DE Brachiaria decumbens E DE DESSECANTES EM PRÉ-COLHEITA SOBRE O RENDIMENTO DE GRÃOS DO FEIJOEIRO E A BIOMASSA FORRAGEIRA EM CULTIVO CONSORCIADO
}

\author{
Effect of sowing dates of Brachiaria decumbens and desiccant in pre-harvest on \\ the yield of grain bean and forage biomass in intercropped system.
}

\author{
Abner José de Carvalho', José Eustáquio de Souza Carneiro², Lino Roberto Ferreira², \\ Paulo Roberto Cecon ${ }^{3}$, Márcia Vitória dos Santos ${ }^{4}$
}

\begin{abstract}
RESUMO
Com o objetivo de avaliar a época de semeadura e os efeitos da dessecação da Brachiaria decumbens em consórcio com duas cultivares de feijão (Phaseolus vulgaris L.), foi conduzido um experimento, em Coimbra, MG, em esquema fatorial envolvendo cultivares de feijão (Ouro Vermelho e VC3), duas épocas de semeadura da braquiária (simultânea e na capina do feijão), três tipos de dessecação (sem dessecação, Carfentrazone-ethil e Paraquat), mais dois tratamentos adicionais: os monocultivos do feijão e da braquiária, em DBC com quatro repetições. O feijoeiro foi plantado com semeadora mecanizada, no espaçamento de $0,50 \mathrm{~m}$ entre linhas. A braquiária foi semeada com semeadora manual, sempre nas entrelinhas do feijoeiro. Foram avaliados o estande final de plantas e o rendimento de grãos do feijão e a biomassa seca da parte aérea da braquiária, aos 15 e aos 60 dias após a colheita do feijão. Concluiu-se que a cultivar Ouro Vermelho é mais indicada para o consórcio com $B$. decumbens na safra das águas que a VC3. O retardamento da semeadura da braquiária proporciona maior rendimento de grãos do feijão, mas prejudica a produção de biomassa seca da forrageira. A dessecação na pré-colheita não influencia a produtividade do feijoeiro, mas, quando é realizada com paraquat, prejudica a produção de biomassa seca da forrageira.
\end{abstract}

Termos para indexação: Integração lavoura-pecuária, formação de pastagens, cultura do feijoeiro.

\begin{abstract}
In order to evaluate different sowing dates and the effect of desiccation on Brachiaria decumbens intercropped with two beans cultivars (Phaseolus vulgaris L.), an experiment was conducted in Coimbra, MG in a factorial design involving two bean cultivars (Ouro Vermelho and VC3), two sowing dates (simultaneous and during bean weeding), three desiccation types (without desiccation, Carfentrazone-ethyl and Paraquat), plus two additional plantings of monoculture bean and brachiaria in DBC with four replications. The beans were seeded by mechanized planting with $0.50 \mathrm{~m}$ spacing between the rows. Brachiaria was sown by manual planting between the bean rows. We evaluated the final stand and grain yield of the beans, and the dry biomass of the brachiaria shoots, at 15 and 60 days after the bean harvest. It was concluded that the cultivar Ouro Vermelho was most suitable for intercropping with $B$. decumbens in the rainy season. Sowing brachiaria after weeding the beans increased the grain yield of the beans, but hindered the production of dry biomass in the brachiaria shoots. Pre-harvest desiccation does not influence the grain yield, but when performed with Paraquat it again hinders the production of dry biomass in brachiaria shoots.
\end{abstract}

Index terms: Crop-livestock integration, formation of pasture, bean crops.

(Recebido em 21 de agosto de 2009 e aprovado em 21 de março de 2011)

\section{INTRODUÇÃO}

A redução da capacidade de produção de áreas potencialmente produtivas é um dos maiores problemas da agropecuária brasileira. Estima-se que atualmente mais da metade dos mais de 170 milhões de hectares destinados a essa atividade no Brasil e cerca de $80 \%$ dos 50 a 60 milhões de hectares de pastagens cultivadas no Brasil Central se encontrem em algum grau de degradação
(MACEDO et al., 2000; PERÓN; EVANGELISTA, 2004), reduzindo sobremaneira a produtividade e a sustentabilidade da agropecuária nacional.

O revigoramento dessas áreas por métodos tradicionais é muito oneroso, em especial pela necessidade de correção e de fertilização. Por isso, a integração lavourapecuária tem se mostrado uma alternativa viável (KLUTHCOUSKI et al., 2004; FERREIRA et al., 2007;

\footnotetext{
1Universidade Estadual de Montes Claros/DCA/UNIMONTES - Avenida Reinaldo Viana, 2630 - Bico da Pedra - $39440-000$ - Janaúba, MG abjocar@yahoo.com.br

2Universidade Federal de Viçosa/UFV - Departamento de Fitotecnia/DFT - Viçosa, MG

${ }^{3}$ Universidade Federal de Viçosa/UFV - Departamento de Informática/DPI - Viçosa, MG

${ }^{4}$ Universidade Federal de Viçosa/UFV - Departamento de Zootecnia/DZO - Viçosa, MG
}

Ciênc. agrotec., Lavras, v. 35, n. 5, p. 893-899, set./out., 2011 
PACHECO et al., 2010), possibilitando a produção de forrageiras de melhor qualidade com menor custo.

O feijão (Phaseolus vulgaris L.) representa boa opção para esse tipo de cultivo, pois é uma cultura bastante apreciada pelos pequenos produtores, possui ciclo curto, é pouco competitiva e relativamente tolerante à competição promovida pela planta consorte, adapta-se muito bem às condições de consórcio, além de frequentemente alcançar bons preços no mercado (VIEIRA, 2006). Todavia, pode haver redução na produtividade das culturas anuais em função da competição promovida pela forrageira. Além do mais, o crescimento excessivo das forrageiras pode dificultar a colheita dos grãos, principalmente quando essa operação é realizada manualmente, como no caso do feijão.

Portanto, para que se obtenha êxito na formação da pastagem, com produção satisfatória da cultura, o plantio antecipado da cultura tem sido utilizado com sucesso no consórcio entre forrageiras tropicais e culturas anuais, como a soja (SILVA et al., 2005) e o milho (FREITAS et al., 2005). Outra opção empregada é o uso de herbicidas dessecantes para facilitar a colheita dos grãos (SILVA et al., 2006). Todavia, ainda não há informações suficientemente seguras sobre a capacidade de rebrota da forrageira nestas condições. Além disso, ainda faltam informações a respeito de cultivares que sejam mais adequados ao sistema de integração lavoura-pecuária.

Conduziu-se este trabalho, com o objetivo de avaliar o desempenho agronômico do consórcio de duas cultivares de feijão com Brachiaria decumbens Stapf. em função da época de semeadura da forrageira e do herbicida usado na dessecação da vegetação antes da colheita do feijão.

\section{MATERIAL E MÉTODOS}

O experimento foi conduzido no campo experimental da Universidade Federal de Viçosa, localizado em Coimbra, MG. O solo da área experimental, classificado como Argissolo Vermelho-Amarelo Câmbico Distrófico, fase terraço (EMPRESA BRASILEIRA DE PESQUISA AGROPECUÁRIA - EMBRAPA, 1999), apresentou as seguintes características químicas: $\mathrm{pH}$ em água: 5,12; saturação por bases (V\%): 41,3; saturação por alumínio (m\%): 3,0; teor de matéria orgânica $\left(\right.$ dag $\left.\mathrm{kg}^{-1}\right): 2,76 ; \mathrm{P}: 19,4$ mg.dm ${ }^{-3} ; \mathrm{K}: 71$ mg.dm ${ }^{-3}$; teores de $\mathrm{Ca}^{+2}, \mathrm{Mg}^{+2} \mathrm{e} \mathrm{H}+\mathrm{Al}: 2,40$; 0,66 e $4,6 \mathrm{cmol}_{\mathrm{c}} \cdot \mathrm{dm}^{-3}$, respectivamente, e P-remanescente: $30,9 \mathrm{mg} \mathrm{L}^{-1}$.

Os tratamentos foram dispostos em esquema fatorial, envolvendo duas cultivares de feijão (Ouro Vermelho e VC3), duas épocas de plantio da braquiária (plantio simultâneo ou na época da capina do feijão), três manejos da dessecação da vegetação (sem dessecação, dessecação com carfentrazone-ethyl e dessecação com paraquat), com dois tratamentos adicionais: monocultivos de feijão e braquiária (B. decumbens cv. Basilisk). $\mathrm{O}$ delineamento experimental utilizado foi o de blocos casualizados, com quatro repetições.

O experimento foi instalado no início de dezembro de 2005, em condição de sequeiro e sistema de preparo convencional de solo, tendo sido realizadas uma gradagem pesada mais uma gradagem leve em pré-plantio. $\mathrm{O}$ feijoeiro foi semeado com semeadora mecanizada ajustada para o espaçamento de $0,50 \mathrm{~m}$ entre linhas e cerca de 15 sementes por metro. A braquiária foi semeada nas entrelinhas do feijoeiro, com auxílio de semeadora manual (matraca), a uma profundidade de 1 a $2 \mathrm{~cm}$, em duas épocas (simultâneo à semeadura do feijoeiro e na época da capina do feijão), utilizando-se para tal cerca de $20 \mathrm{~kg} \mathrm{ha}^{-1}$ de sementes com valor cultural (VC) de $32 \%$. As principais ocorrências climáticas verificadas durante o período de condução dos experimentos são apresentadas na Figura 1.

A área total de cada parcela foi de $12,5 \mathrm{~m}^{2}$ ( 5 fileiras com $5 \mathrm{~m}$ de comprimento), no caso do feijoeiro, e de $10 \mathrm{~m}^{2}$ (4 fileiras de $5 \mathrm{~m}$ ) no caso da braquiária. A área útil foi de $6 \mathrm{~m}^{2}$ ( 3 fileiras de $4 \mathrm{~m}$ ) e de $2 \mathrm{~m}^{2}$ ( 2 fileiras centrais de $2 \mathrm{~m}$ ), para o feijoeiro e para a braquiária, respectivamente.

O cálculo da necessidade de calagem (ALVAREZ; RIBEIRO, 1999) estimou a necessidade de 1,50 ton. ha ${ }^{-1}$ de calcário dolomítico, cuja aplicação foi realizada com distribuição em área total e incorporação ao solo, por meio das operações de preparo do solo. O feijoeiro foi adubado com $250 \mathrm{~kg} \mathrm{ha}^{-1}$ da formulação NPK 08:28:16 na operação de semeadura, adicionado de $30 \mathrm{~kg} \mathrm{ha}^{-1}$ de $\mathrm{N}$ como adubação de cobertura, de acordo com a recomendação oficial para Minas Gerais, para o nível 2 de tecnologia (CHAGAS et al., 1999). Além disso, foi realizada uma aplicação de $40 \mathrm{~g} \mathrm{ha}^{-1}$ de molibdênio via foliar, utilizando-se molibdato de sódio como fonte. A braquiária, por sua vez, não foi adubada nem na semeadura, nem em cobertura.

Nos sistemas de consórcio foi realizado controle das plantas daninhas eudicotiledôneas, por meio da aplicação dos herbicidas fomesafen $\left(125 \mathrm{~g} \mathrm{ha}^{-1}\right) \mathrm{e}$ bentazon (336 $\left.\mathrm{g} \mathrm{ha}^{-1}\right)$. No monocultivo do feijoeiro, foram aplicados os herbicidas fomesafen $\left(125 \mathrm{~g} \mathrm{ha}^{-1}\right)$ e fluazifopp-butyl (100 $\left.\mathrm{g} \mathrm{ha}^{-1}\right)$. A braquiária em monocultivo foi capinada manualmente com enxada. O manejo das plantas daninhas ocorreu aos 25 DAE. A dessecação ocorreu três dias antes da colheita do feijão, realizada aos 85 DAE, com os herbicidas com carfentrazone-ethyl $\left(20 \mathrm{~g} \mathrm{ha}^{-1}\right) \mathrm{e}$ paraquat $\left(400 \mathrm{~g} \mathrm{ha}^{-1}\right)$. 


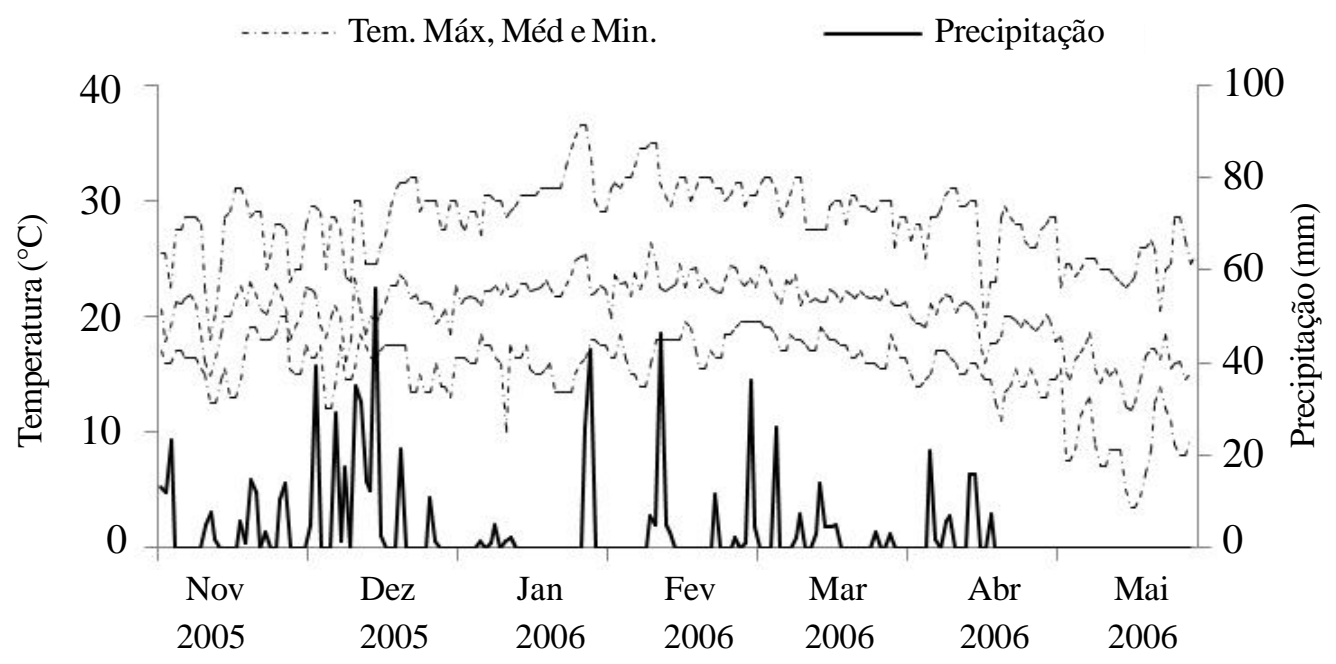

Figura 1 - Variação diária das médias de temperatura máxima, média e mínima (dados fornecidos pelo INMET) e precipitação pluviométrica (dados coletados no Campo Experimental de Coimbra, MG), no período de novembro de 2005 a maio de 2006.

No feijoeiro, foram avaliados o estande final de plantas (mil plantas ha-1) e o rendimento de grãos $\left(\mathrm{kg} \mathrm{ha}^{-1}\right)$. O estande final foi estimado a partir da contagem do número total de plantas de cada parcela, enquanto o rendimento de grãos foi obtido por meio da pesagem dos grãos colhidos na área útil de cada parcela, considerando-se a umidade de $13 \%$. Na braquiária, avaliou-se a biomassa seca da parte aérea aos 15 e aos 60 dias após a colheita do feijoeiro(DACF). Para a estimativa da massa seca, as plantas de braquiária foram cortadas rente ao solo. Em seguida, as amostras foram secas em estufa a $70^{\circ} \mathrm{C}$, por 72 horas, para posterior pesagem. Aos $15 \mathrm{DACF}$, em razão dos efeitos dos herbicidas dessecantes, o corte das plantas foi realizado apenas nos tratamentos sem dessecação. As avaliações realizadas aos 15 e aos 60 DACF ocorreram em pontos distintos, dentro da área útil de cada parcela.

Os dados foram submetidos à análise de variância. Os genótipos de feijão e as épocas de semeadura da braquiária foram comparados pelo teste $\mathrm{F}$ a $5 \%$ de probabilidade, enquanto os efeitos da dessecação foram estudados pelo teste de Tukey a 5\% de probabilidade. Além disso, foram realizados alguns contrastes entre tratamentos do monocultivo e do consórcio, que foram comparados pelo teste $\mathrm{F}$ a $5 \%$ de probabilidade.

\section{RESULTADOSE DISCUSSÃO}

As cultivares de feijão $(\mathrm{Ge})$ apresentaram diferenças significativas em relação ao estande final de plantas e ao rendimento de grãos do feijoeiro. A época de semeadura da braquiária (ES) afetou significativamente o rendimento de grãos do feijão e a produção de biomassa seca da forrageira aos 15 e aos 60 DACF. A dessecação (D) influenciou a produção de biomassa seca da braquiária aos 60 DACF. Ainteração Ge x ES foi significativa apenas para a produção de biomassa seca da braquiária aos 15 DACF, enquanto as demais interações não foram significativas para nenhuma das características avaliadas.

O desdobramento da interação entre cultivar de feijão e a época de semeadura da braquiária revelou que, aos $15 \mathrm{DACF}$, para a braquiária semeada na época da capina do feijão não houve diferença na produção de massa seca em função do genótipo de feijão. Entretanto, no plantio simultâneo, a braquiária consorciada com a cultivar Ouro Vermelho apresentou produção de biomassa seca em torno de $65 \%$ superior à alcançada no consórcio com o VC3 (Tabela 1). Silva et al. (2006) estudaram o consórcio de duas cultivares de feijão com B. brizantha (Hochst. ex A. Rich.) Stapf. e também verificaram que a cultivar de porte mais ereto mostrou-se mais adequada ao plantio consorciado com braquiária na safra das águas.

$\mathrm{Na}$ avaliação realizada aos $15 \mathrm{DACF}$, a produção de biomassa seca da braquiária semeada na época da capina do feijoeiro foi menor que a obtida nos tratamentos em que a forrageira foi semeada simultaneamente ao feijoeiro, independentemente do cultivar de feijão utilizado no consórcio (Tabela 1). Esse resultado está relacionado com a maior competição promovida pelo feijoeiro nos casos em que o plantio da braquiária foi retardado. 
A cultivar Ouro Vermelho apresentou maiores valores de estande final e de rendimento de grãos que a VC3 (Tabela 2). A precocidade, característica de VC3, geralmente está relacionada com um menor rendimento de grãos (COIMBRA et al., 2000). Além disso, enquanto a cultivar Ouro Vermelho apresenta porte semiereto, a VC3 tem porte prostrado, o que confere à primeira, condições mais favoráveis na competição pela luz e um melhor arejamento do ambiente, que contribui para reduzir a incidência de doenças, especialmente na safra das águas (RAMALHO; ABREU, 2006).

A produção de biomassa seca da forrageira aos 60 DACF, não foi influenciada pelas cultivares de feijão (Tabela 2), o que indica que a maior produtividade da Ouro Vermelho não interferiu negativamente na produção da braquiária. O porte mais ereto dessa cultivar em relação a VC3 pode ter proporcionado também uma menor competição por luz e maior arejamento do ambiente, compensando uma possível maior competição por água e/ ou nutrientes requeridos pelo cultivar mais produtivo.

O rendimento de grãos do feijão foi maior quando a braquiária foi semeada na época da capina do feijoeiro, em comparação ao consorciado com a forrageira em plantio simultâneo (Tabela 2). O maior tempo de convivência entre as plantas é um dos fatores que determinam o grau de interferência na competição interespecífica (PITELLI, 1985; ZANINE; SANTOS, 2004). Assim, na semeadura simultânea a maior competição promovida pela braquiária pode ter prejudicado o rendimento de grãos do feijoeiro.

Em contrapartida, mesmo aos $60 \mathrm{DACF}$, a produção de biomassa seca da braquiária semeada simultaneamente ao feijoeiro foi maior que a obtida pela forrageira semeada na capina (Tabela 2). De acordo com Portes et al. (2003), enquanto as gramíneas forrageiras tropicais, especialmente as braquiárias, são conhecidas pelo seu lento acúmulo inicial de matéria seca, até aproximadamente 50 dias da emergência,

Tabela 1 - Biomassa seca da parte aérea da Brachiaria decumbens aos 15 dias após a colheita do feijão cultivado em consórcio na safra das águas de 2005-2006, em função da interação entre a época de plantio da forrageira e o genótipo de feijão.

\begin{tabular}{lccc}
\hline & $\begin{array}{c}\text { Épocas de plantio } \\
\text { da braquiária }\end{array}$ & \multicolumn{3}{c}{ Genótipos de feijão } \\
\cline { 2 - 4 } & Ouro Vermelho & VC3 \\
\hline Simultâneo & $1598 \mathrm{aA}^{1 /}$ & $970 \mathrm{aB}$ \\
Capina & $154 \mathrm{bA}$ & $215 \mathrm{bA}$ \\
\hline
\end{tabular}

${ }^{1 / D e n t r o ~ d e ~ c a d a ~ f a t o r, ~ m e ́ d i a s ~ s e g u i d a s ~ p o r ~ d i f e r e n t e s ~ l e t r a s ~ d i f e r e m ~ s i g n i f i c a t i v a m e n t e ~ p e l o ~ t e s t e ~} \mathrm{~F}$ a $5 \%$ de probabilidade. Letras minúsculas comparam as épocas de plantio da braquiária, enquanto as maiúsculas comparam os genótipos de feijão.

Tabela 2 - Estande final de plantas (EF) e rendimento de grãos (RG) do feijoeiro e biomassa seca da braquiária aos 60 dias (MS-60) após a colheita do feijão, em sistema de consórcio, na safra das águas de 2005-2006

\begin{tabular}{|c|c|c|c|}
\hline Tratamentos & 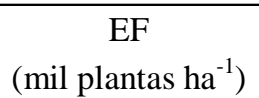 & $\begin{array}{c}\mathrm{RG} \\
\left(\mathrm{kg} \mathrm{ha}^{-1}\right)\end{array}$ & $\begin{array}{l}\text { MS-60 } \\
\left(\mathrm{kg} \mathrm{ha}^{-1}\right)\end{array}$ \\
\hline \multicolumn{4}{|c|}{ Cultivares de feijão } \\
\hline Ouro Vermelho & $237 \mathrm{a}^{1 /}$ & $1753 \mathrm{a}$ & $9747 \mathrm{a}$ \\
\hline VC3 & $215 \mathrm{~b}$ & $1131 \mathrm{~b}$ & 8994 a \\
\hline \multicolumn{4}{|c|}{ Épocas de plantio } \\
\hline Simultâneo & $223 \mathrm{a}$ & $1282 \mathrm{~b}$ & $14866 \mathrm{a}$ \\
\hline Capina & $229 \mathrm{a}$ & $1602 \mathrm{a}$ & $3876 \mathrm{~b}$ \\
\hline \multicolumn{4}{|l|}{ Dessecação } \\
\hline Sem dessecação & $230 \mathrm{a}$ & $1546 \mathrm{a}$ & $11650 \mathrm{a}$ \\
\hline Carfentrazone-ethyl & $226 \mathrm{a}$ & $1397 \mathrm{a}$ & $11821 \mathrm{a}$ \\
\hline Paraquat & $221 \mathrm{a}$ & $1383 \mathrm{a}$ & $4641 \mathrm{~b}$ \\
\hline $\mathrm{CV}(\%)$ & 10,53 & 25,94 & 53,91 \\
\hline
\end{tabular}

${ }^{1 / D e n t r o ~ d e ~ c a d a ~ f a t o r, ~ m e ́ d i a s ~ s e g u i d a s ~ p o r ~ d i f e r e n t e s ~ l e t r a s ~ n a s ~ c o l u n a s ~ d i f e r e m ~ s i g n i f i c a t i v a m e n t e ~ p e l o ~ t e s t e ~} \mathrm{~F}$ (genótipos de feijão e épocas de plantio da braquiária) ou pelo teste de Tukey (dessecação), a 5\% de probabilidade.

Ciênc. agrotec., Lavras, v. 35, n. 5, p. 893-899, set./out., 2011 
a maioria das culturas anuais cresce rapidamente no início do ciclo. Assim, o maior sombreamento produzido pelo feijoeiro pode prejudicar ainda mais o desenvolvimento da braquiária semeada tardiamente. Silva et al. (2005) verificaram que quanto mais tardio foi o plantio de $B$. brizantha em consórcio com soja, menor foi o acúmulo de matéria seca da forrageira e maior a produção de grãos de soja.

A dessecação da vegetação na pré-colheita do feijão não influenciou nenhuma das características avaliadas no feijoeiro. Por sua vez, a produção de biomassa seca da forrageira, nos tratamentos em que o paraquat foi utilizado na dessecação, foi de apenas cerca de $40 \%$ da alcançada nos demais tratamentos. Já o carfentrazone-ethyl, que não tem efeito sobre a braquiária, não prejudicou a produção de biomassa da forrageira (Tabela 2).

A cultivar Ouro Vermelho apresentou maior rendimento de grãos que o VC3 também no monocultivo (Contraste v1, Tabela 3). Este resultado está relacionado a algumas características intrínsecas das cultivares, como precocidade e porte, que favorecem a Ouro Vermelho, principalmente na safra das águas. Os demais contrastes não foram significativos (Contrastes v2 a v7, Tabela 3), evidenciando que o rendimento de grãos do feijoeiro não foi afetado negativamente pelo consórcio com a braquiária.

Mesmo no monocultivo, a braquiária semeada tardiamente apresentou menor produção de massa seca que a semeada na mesma época que o feijoeiro (Contraste v1, Tabela 4). Esse resultado indica que a redução de produção de biomassa da braquiária semeada na época da capina do feijão no consórcio (Tabela 2) pode estar relacionada também a um possível efeito das condições climáticas (Figura 1), principalmente da menor ocorrência de chuvas, sobre a germinação e o desenvolvimento da forrageira semeada tardiamente.

Para cada época de semeadura, a produção de biomassa seca da braquiária no monocultivo foi equivalente à obtida no consórcio (Contrastes v2 e v3, Tabela 4), tanto aos 15 quanto aos 60 DACF. De maneira semelhante, para cada tipo de dessecação estudado, a produção de massa seca da braquiária em monocultivo, aos $60 \mathrm{DACF}$, foi equivalente à obtida em consórcio com o feijão (Contrastes v4 a v6, Tabela 4). Esses resultados evidenciam que o consórcio com o feijão não prejudicou o estabelecimento da pastagem. Portes et al. (2000), estudaram o crescimento de $B$. brizantha em monocultivo e em consórcio com cereais e verificaram que a presença das culturas prejudicou o crescimento da forrageira até o momento da colheita. Entretanto, 70 dias após a colheita dos cereais, a forrageira consorciada apresentou biomassa seca equivalente à obtida pela braquiária em monocultivo aos 70 dias após a emergência.

A dessecação com paraquat prejudicou a produção de biomassa seca da braquiária também no monocultivo (Contrastes v7 a v9, Tabela 4) Aos $60 \mathrm{DACF}$, a produção de massa seca da braquiária solteira dessecada com esse herbicida foi de apenas cerca de 17 e $23 \%$ da alcançada pela forrageira dessecada com carfentrazone-ethyl ou pelos tratamentos sem dessecação, respectivamente.

Tabela 3 - Contrastes entre médias do monocultivo e do consórcio, com os respectivos valores médios de rendimento de grãos do feijão cultivado em consórcio com Brachiaria decumbens na safra das águas de 2005-2006 .

\begin{tabular}{ccc}
\hline & Contrastes & $\begin{array}{c}\text { Rendimento } \\
\left(\mathrm{kg} \mathrm{ha}^{-1}\right)\end{array}$ \\
\hline$\hat{Y} 1$ & Ouro Vermelho (Monocultivo) & $1850 \mathrm{a}$ \\
& VC3 (Monocultivo) & $1155 \mathrm{~b}$ \\
\hline$\hat{Y} 2$ & Ouro Vermelho (plantio simultâneo) & $1684 \mathrm{a}$ \\
& Ouro Vermelho (Monocultivo) & $1850 \mathrm{a} \mathrm{a}$ \\
\hline$\hat{Y} 3$ & VC3 (plantio simultâneo) & $879 \mathrm{a}$ \\
& VC3 (Monocultivo) & $1155 \mathrm{a}$ \\
\hline$\hat{Y} 4$ & Ouro Vermelho (capina) & $1915 \mathrm{a}$ \\
& Ouro Vermelho (Monocultivo) & $1850 \mathrm{a}$ \\
\hline$\hat{Y} 5$ & VC3 (capina) & $1381 \mathrm{a}$ \\
& VC3 (Monocultivo) & $1155 \mathrm{a}$ \\
\hline$\hat{Y} 6$ & Ouro Vermelho (Monocultivo) & $1850 \mathrm{a}$ \\
& Ouro Vermelho (Consórcio) & $1753 \mathrm{a}$ \\
\hline$\hat{Y} 7$ & VC3 (Monocultivo) & $1155 \mathrm{a}$ \\
& VC3 (Consórcio) & $1130 \mathrm{a}$ \\
\hline
\end{tabular}

${ }^{1}$ Dentro de cada contraste, médias seguidas por diferentes letras nas colunas diferem significativamente pelo teste $\mathrm{F}$ a $5 \%$ de probabilidade. 
Tabela 4 - Contrastes entre médias do monocultivo e do consórcio, com os respectivos valores médios de biomassa seca da parte aérea da Brachiaria decumbens aos 15 (MS-15) e aos 60 dias após a colheita do feijão (MS-60) cultivado em sistema de consórcio na safra das águas de 2005-2006².

\begin{tabular}{|c|c|c|c|}
\hline & Contrastes & $\begin{array}{c}\text { MS-15 } \\
\left(\mathrm{kg} \mathrm{ha}^{-1}\right)\end{array}$ & $\begin{array}{c}\text { MS-60 } \\
\left(\mathrm{kg} \mathrm{ha}^{-1}\right)\end{array}$ \\
\hline \multirow{2}{*}{$\hat{\mathrm{Y}} 1$} & Semeadura simultânea (Monocultivo) & $1112 \mathrm{a}$ & $14506 \mathrm{a}$ \\
\hline & Semeadura na capina (Monocultivo) & $116 \mathrm{~b}$ & $1515 \mathrm{~b}$ \\
\hline \multirow{2}{*}{$\hat{\mathrm{Y}} 2$} & Semeadura simultânea (Monocultivo) & $1112 \mathrm{a}$ & $14506 \mathrm{a}$ \\
\hline & Semeadura simultânea (Consórcio) & $1284 \mathrm{a}$ & $14866 \mathrm{a}$ \\
\hline \multirow{2}{*}{$\hat{\mathrm{Y}} 3$} & Semeadura na capina (Monocultivo) & $116 \mathrm{a}$ & $1515 \mathrm{a}$ \\
\hline & Semeadura na capina (Consòrcio) & $185 \mathrm{a}$ & $3875 \mathrm{a}$ \\
\hline \multirow{2}{*}{$\hat{\mathrm{Y}} 4$} & Sem dessecação (Monocultivo) & - & 9358 a \\
\hline & Sem dessecação (Consórcio) & - & $11650 \mathrm{a}$ \\
\hline \multirow{2}{*}{$\hat{Y} 5$} & Dessecação Carfentrazone (Monocultivo) & - & $12486 \mathrm{a}$ \\
\hline & Dessecação Carfentrazone (Consórcio) & - & $11821 \mathrm{a}$ \\
\hline \multirow{2}{*}{$\hat{\mathrm{Y}} 6$} & Dessecação Paraquat (Monocultivo) & - & $2188 \mathrm{a}$ \\
\hline & Dessecação Paraquat (Consórcio) & - & $4641 \mathrm{a}$ \\
\hline \multirow{2}{*}{$\hat{\mathrm{Y}} 7$} & Sem dessecação (Monocultivo) & - & 9358 a \\
\hline & Dessecação Carfentrazone (Monocultivo) & - & $12486 \mathrm{a}$ \\
\hline \multirow{2}{*}{$\hat{\mathrm{Y}} 8$} & Sem Dessecação (Monocultivo) & - & 9358 a \\
\hline & Dessecação Paraquat (Monocultivo) & - & $2188 \mathrm{~b}$ \\
\hline \multirow{2}{*}{$\hat{\mathrm{Y}} 9$} & Dessecação Carfentrazone (Monocultivo) & - & $12486 \mathrm{a}$ \\
\hline & Dessecação Paraquat (Monocultivo) & - & $2188 \mathrm{~b}$ \\
\hline
\end{tabular}

${ }^{1}$ Dentro de cada contraste, médias seguidas por diferentes letras nas colunas diferem significativamente pelo teste $\mathrm{F}$ a $5 \%$ de probabilidade.

\section{CONCLUSÕES}

A cultivar Ouro Vermelho é mais indicada para o consórcio com $B$. decumbens na safra das águas que a VC3, pois, em razão do porte ereto, alcança bom rendimento de grãos sem prejudicar a formação da pastagem.

O retardamento da semeadura da braquiária proporciona maior rendimento de grãos do feijão, mas prejudica a produção de biomassa seca da forrageira.

A dessecação na pré-colheita não influencia a produtividade do feijoeiro, mas, quando é realizada com paraquat, prejudica a produção de biomassa seca da forrageira.

\section{AGRADECIMENTOS}

À Fundação de Amparo à Pesquisa do Estado de Minas Gerais (FAPEMIG) e ao Conselho Nacional de Desenvolvimento Científico e Tecnológico (CNPq).

\section{REFERÊNCIASBIBLIOGRÁFICAS}

ALVAREZ, V.H.; RIBEIRO, A.C. Calagem. In: RIBEIRO, A.C.; GUIMARÃES, P.T.G; ALVAREZ, V.H.

Recomendações para o uso de corretivos e fertilizantes em Minas Gerais: 5 a aproximação. Viçosa, MG: CFSEMG, 1999. p.43-60.

CHAGAS, J.M. et al. Feijão. In: COMISSÃO DE FERTILIDADE DO SOLODOESTADO DE MINAS GERAIS. Recomendações para o uso de corretivos e fertilizantes em Minas Gerais: $5^{a}$ aproximação. Viçosa, MG 1999. p.306-307.

COIMBRA, J.L.M. et al. Correlações canônicas: II., análise do rendimento de grãos de feijão e seus componentes. Ciência Rural, Santa Maria, v.30, n.1, p.31-35, 2000 . 
EMPRESA BRASILEIRA DE PESQUISA AGROPECUÁRIA. Sistema brasileiro de classificação de solos. Brasília, 1999. 412p.

FERREIRA, L.R. et al. Formação de pastagens em sistema de integração. Informe Agropecuário, Belo Horizonte, v.28, n.240, p.52-62, set./out. 2007.

FREITAS, F.C.L. et al. Cultivo consorciado de milho para silagem com Brachiaria brizantha no sistema de plantio convencional. Planta Daninha, Viçosa, v.23, n.4, p.635644, 2005.

KLUTHCOUSKI, J. et al. Integração lavoura-pecuária e o manejo de plantas daninhas. Informações Agronômicas, Piracicaba, n. 106, 2004.

MACEDO, M.C.M.; KICHEL, A.N.; ZIMMER, A.H. Degradação e alternativas de recuperação e renovação de pastagens. Brasília: Embrapa Cerrado, 2000. 4p. (Comunicado técnico, 62).

PACHECO, L.P. et al. Profundidade de semeadura e crescimento inicial de espécies forrageiras utilizadas para cobertura do solo. Ciência e Agrotecnologia, Lavras, v.34, n.5, out. 2010. Disponível em: <http:// www.scielo.br/scielo.php?script=sci_arttext\&pid=S141370542010000500019\&lng=pt\&nrm=iso $>$. Acesso em: 30 mar. 2011.

PERON, A.J.; EVANGELISTA, A.R. Degradação de pastagens em regiões de cerrado. Ciência e

Agrotecnologia, Lavras, v.28, n.3, jun. 2004. Disponível em: <http://www.scielo.br/ scielo.php?script =sci_artte xt\&pid=S1413-7054200 $4000300023 \& \operatorname{lng}=$ pt\&nrm=iso $>$. Acesso em: 30 mar. 2011.
PITELLI, R.A. Interferência de plantas daninhas em culturas agrícolas. Informe Agropecuário, Belo Horizonte, v.11, n.129, p.16-27, 1985.

PORTES, T. de A.; CARVALHO, S.I.C. de; KLUTHCOUSKI, J. Aspectos fisiológicos das plantas cultivadas e análise de crescimento da braquiária consorciada com cereais. In: KLUTHCOUSKI, J.; STONE, L.F.; AIDAR, H. (Eds.). Integração lavourapecuária. Santo Antônio de Goiás: Embrapa Arroz e Feijão, 2003. p.303-329.

PORTES, T. de A. et al. Análise do crescimento de uma cultivar de braquiária em cultivo solteiro e consorciado com cereais. Pesquisa Agropecuária Brasileira, Brasília, v.35, n.7, p.1349-1358, jul. 2000.

RAMALHO, M.A.P.; ABREU, A. de F.B. Cultivares. In: VIEIRA, C.; PAULA JÚNIOR, T.J. de; BORÉM, A. Feijão. 2.ed. Viçosa, MG: UFV, 2006. p.415-436.

SILVA, A.C. et al. Consórcio entre feijão e Brachiaria decumbens sob doses reduzidas de graminicida. Planta daninha, Viçosa, v.24, n.1, p.71-76, 2006.

SILVA, A.C. et al. Épocas de emergência de B. brizantha no desenvolvimento da cultura da soja. Ciência Rural, Santa Maria, v.35, n.4, p.769-775, jul./ago. 2005.

VIEIRA, C. Cultivos consorciados. In: VIEIRA, C.; PAULA JÚNIOR, T.J. de; BORÉM, A. Feijão. 2.ed. Viçosa, MG: UFV, 2006. p.493-528.

ZANINE, A. de M.; SANTOS, E.M. Competição entre espécies de plantas: uma revisão. Revista da FZVA, Uruguaiana, v.11, n.1, p.10-30, 2004. 